\title{
Shock Tube Studies on the Decomposition of 2-Butanol
}

\author{
Claudette M. Rosado-Reyes* ${ }^{*}$, and Wing Tsang \\ National Institute of Standards and Technology (NIST), Gaithersburg, MD, USA \\ * Corresponding author: claudette.rosado-reyes@nist.gov
}

This work is aimed at providing fundamental or transferable chemical kinetics data for biofuels to combustion databases, for prediction purposes. The amount of kinetic information needed for simulation is immense, making not possible to have experimental measurements for every reaction. A striking example is the case of mixtures. Any possible use of biofuels will be in combination with petroleum based substances. Fundamental information represents data that lead directly to mixing rules that cannot be determined on any other basis. The greatest difference in the fundamental reaction processes between any two fuels is the initial radical formation and decomposition processes. Once the primary radicals are formed upon initial thermal decomposition, their subsequent reactions become increasingly similar as combustion progresses ultimately leading to the production of carbon dioxide, water or soot. Much of the existing kinetic databases are based on rate rules derived either empirically or through ab-initio calculations. The uncertainties in these estimates are vague. This is especially the case as fuel molecules become larger. Unambiguous experimental results are important not only for the purposes of simulations but also as a basis for calibrating estimates.

The experiments were carried out in a heated single pulse shock tube(1). The key features of these experiments are the dilute concentrations of the test mixture, of the order of $500 \mathrm{ppm} \mathrm{2-}$ butanol, and the large excesses of a chemical inhibitor, 1\% 1,3,5-trimethylbenzene. The chemical inhibitor captures all the reactive radicals that are formed, thus only unimolecular reactions contribute to the product yields. This internal standard approach makes certain that the nonidealities in the shock tube study are experienced by both target molecules. Therefore results from the shock tube study are traceable and transferable and provide the basic information necessary for developing the relationships between the behaviors of all fuels that have been studied.

The determined rate expressions for main initial decomposition processes in 2-butanol are,

$$
\begin{aligned}
& k\left(\mathrm{C}_{3} \mathrm{H}_{6}(\mathrm{OH}) \mathrm{CH}_{3} \rightarrow(\mathrm{Z})-\mathrm{CH}_{3} \mathrm{CH}=\mathrm{CHCH}_{3}+\mathrm{H}_{2} \mathrm{O}\right)=1.41 \times 10^{13} \exp (-33414 / \mathrm{T}[\mathrm{K}]) \mathrm{s}^{-1} \\
& k\left(\mathrm{C}_{3} \mathrm{H}_{6}(\mathrm{OH}) \mathrm{CH}_{3} \rightarrow(\mathrm{E})-\mathrm{CH}_{3} \mathrm{CH}=\mathrm{CHCH}_{3}+\mathrm{H}_{2} \mathrm{O}\right)=2.90 \times 10^{13} \exp (-33820 / \mathrm{T}[\mathrm{K}]) \mathrm{s}^{-1} \\
& k\left(\mathrm{C}_{3} \mathrm{H}_{6}(\mathrm{OH}) \mathrm{CH}_{3} \rightarrow \mathrm{CH}_{3} \mathrm{CH}_{2} \mathrm{CH}=\mathrm{CH}_{2}+\mathrm{H}_{2} \mathrm{O}\right)=3.57 \times 10^{13} \exp (-33002 / \mathrm{T}[\mathrm{K}]) \mathrm{s}^{-1} \\
& k\left(\mathrm{C}_{3} \mathrm{H}_{6}(\mathrm{OH}) \mathrm{CH}_{3} \rightarrow \mathrm{CH}_{3} \mathrm{CH}_{2}{ }^{*}+{ }^{*} \mathrm{CH}(\mathrm{OH}) \mathrm{CH}_{3}=7.40 \times 10^{15} \exp (-39252 / \mathrm{T}[\mathrm{K}]) \mathrm{s}^{-1}\right.
\end{aligned}
$$

Comparison with estimates in the literature illustrates the diversity of the predictions based on various methodologies, with no any obvious internal consistencies.

The present results are compared with earlier data from single pulse shock tube studies on other larger alcohols(2,3). Water elimination is a major channel. General trends with respect to methyl substitution can be derived. The dependence on methyl ejection is however much weaker than the in alkyl halides. An $\mathrm{OH}$ group adjacent to the bond being broken increases the rate constants for bond breaking. The presence of the $\mathrm{OH}$ group beta to the bond being broken has negligible effects.

\section{References}

(1) Awan, I.A.; McGivern, W.S.; Tsang, W.; Manion, J.A. J. Phys. Chem. A 2010, 144, 78327846.

(2) Rosado-Reyes, C.M.; Tsang W."Shock Tube Study on the Thermal Decomposition of nButanol", Proceedings of the Combustion Institute, submitted.

(3) Tsang, W. Int. J. Chem. Kinet. 1976, 8, 173-192. 